\title{
Trihaloisocyanuric Acids/NaX: an Environmentaly Friendly System for Vicinal Dihalogenation of Alkenes without using Molecular Halogen
}

\author{
Suellen D. F. Tozetti, Leonardo S. de Almeida, Pierre M. Esteves* and Marcio C. S. de Mattos* \\ Instituto de Química, Departamento de Química Orgânica, Universidade Federal do Rio de Janeiro, \\ CP 68545, 21945-970 Rio de Janeiro, Brazil
}

\begin{abstract}
A reação de alquenos com ácidos trialo-isocianúricos / $\mathrm{NaX}$ em acetona aquosa produz os dialo-alcanos vicinais em rendimentos de moderados a excelentes

The reaction of alkenes with easily handled trihaloisocyanuric acids / $\mathrm{NaX}$ in aqueous acetone produces the corresponding vicinal dihaloalkanes in moderate to excellent yields.
\end{abstract}

Keywords: dihaloalkanes, electrophilic addition, green chemistry, trihaloisocyanuric acid

\section{Introduction}

The great synthetic potential of organic halides puts them in a unique position within organic chemistry. They can be efficiently converted into other functionality by well-known methodologies, such as halogen-metal exchange, palladium-catalyed reaction for new C-C bond formation, conversion into radicals, nucleophilic substitution etc. ${ }^{1}$ Furthermore, several marine organic halides have been discovered in the last years with interesting biological activity. ${ }^{2}$

Although several reagents have been used to introduce halogen atoms in organic substrates, the typical route to prepare vicinal dihalo compounds is the electrophilic molecular halogen $\left(\mathrm{X}_{2}\right)$ addition to alkenes. ${ }^{3}$ Molecular chlorine $\left(\mathrm{Cl}_{2}\right)$ is a very toxic gas that presents a potential hazard and its quantitative utilization is generally problematical. Molecular bromine $\left(\mathrm{Br}_{2}\right)$ is a toxic and lowboiling lachrymatory liquid which causes severe burns on contact with skin. Moreover, both halogens are corrosive, difficult to handle and strong oxidants. ${ }^{4}$ In addition, traditional halogenations of alkenes are performed in polychlorinated solvents, such as $\mathrm{CHCl}_{3}$ or $\mathrm{CCl}_{4}$ which are being considered "villains" from the green chemistry point of view. ${ }^{5}$ Furthermore, in chlorinated solvents, free radical reaction can compete to electrophilic process and some by products are usually obtained. ${ }^{6}$

Based on the above considerations, the search for new methodologies that avoid the utilization of molecular

*e-mail: pesteves@iq.ufrj.br; mmattos@iq.ufrj.br halogen is of great interest and attractive. Unfortunately, some alternative reagents used for dihalogenation of alkenes are very hazardous, toxic, not readily available or need to be freshly prepared. ${ }^{7}$

Trichloroisocyanuric acid (TCCA) is a stable and inexpensive solid frequently used for swimming-pool disinfection and easily available in pool supply and some hardware stores. ${ }^{8}$ Tribromoisocyanuric acid (TBCA), an analogue of TCCA, is easily and safely prepared from cyanuric acid, $\mathrm{KBr}$ and oxone. ${ }^{9}$ We have shown that these trihaloisocyanuric acids are very interesting from Green Chemistry point of view, once they are easily handled stable solids and efficient source of electrophilic halenium ions $\left(\mathrm{X}^{+}\right)$ that can halogenate organic compounds without using $\mathrm{X}_{2}{ }^{10}$ They also present a very good atom economy, once they can transfer most part of their mass to the substrate. For example, TBCA can transfer up to $65 \%$ of its mass to the substrate. Furthermore, in these reactions, cyanuric acid precipates as by-product, which can be recovered by filtration and reused to prepare more TBCA (Scheme 1).

Herein we communicate our results on the utilization of trihaloisocyanuric acids to perform the vicinal dihalogenation of alkenes.

\section{Results and Discussion}

The reactions of alkenes with TCCA in the presence of chloride ion or with TBCA in the presence of bromide ion produced the vicinal dihaloalkanes. The reactions were carried out stirring together $10 \mathrm{mmol}$ of the alkene (cyclohexene, 1-methylcyclohexene, styrene, $\alpha$-methyl- 


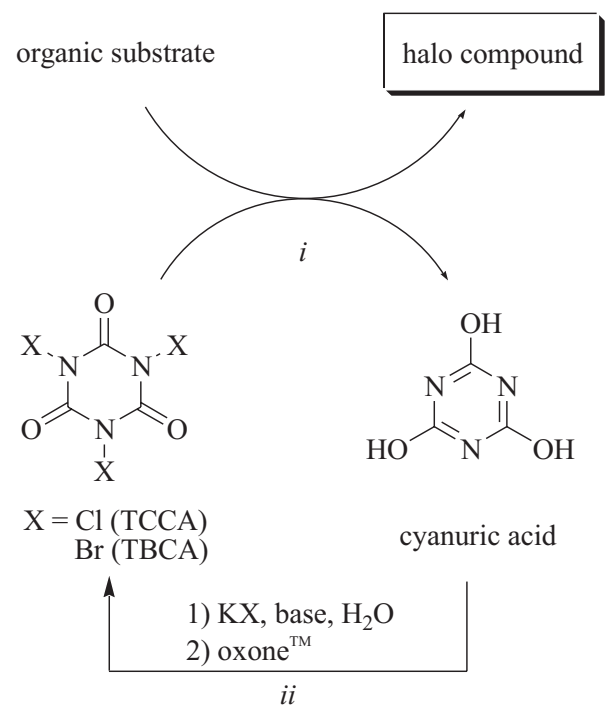

Scheme 1. (i) related to reference 10; (ii) related to reference 9.

styrene, or 1-octene,) with $3.4 \mathrm{mmol}$ of the corresponding trihaloisocyanuric acid and $5 \mathrm{mmol}$ of the halide in aqueous acetone at room temperature. ${ }^{11}$ The end of the reactions were determined when an aliquot did not produce a color change in a wet iodide-starch test paper. After work up, cyanuric acid was filtered off and the corresponding vicinal dihaloalkanes were obtained in moderate to excellent yields. The products were characterized by GCMS, physical constants and coinjection with authentic samples in HRGC. Table 1 summarizes the obtained results.

In the investigation of the actual halogenating reagent, we studied the reaction of cyclohexene with TCCA / Br and TBCA $/ \mathrm{Cl}^{-}$and obtained a mixture of several products, among of them trans-1-bromo-2-chlorocyclohexane.

Table 1. Yields of vicinal dihaloalkanes

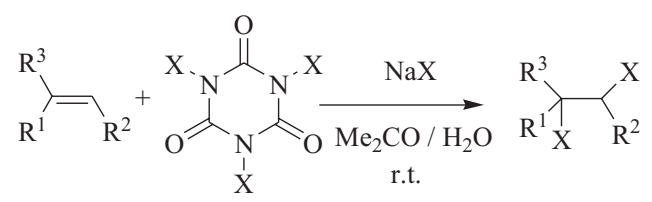

\begin{tabular}{lccccc}
\hline $\mathrm{R}^{1}$ & $\mathrm{R}^{2}$ & $\mathrm{R}^{3}$ & $\mathrm{X}$ & $\mathrm{t} / \mathrm{h}$ & Yield $(\%)^{\mathrm{a}}$ \\
\hline$-\left(\mathrm{CH}_{2}\right)_{4}$ & - & $\mathrm{H}$ & $\mathrm{Cl}$ & 5.0 & $76^{\mathrm{b}}$ \\
$-\left(\mathrm{CH}_{2}\right)_{4}$ & - & $\mathrm{H}$ & $\mathrm{Br}$ & 0.5 & $59^{\mathrm{b}}$ \\
$-\left(\mathrm{CH}_{2}\right)_{4}$ & - & $\mathrm{Me}$ & $\mathrm{Cl}$ & 1.5 & $93^{\mathrm{b}}$ \\
$-\left(\mathrm{CH}_{2}\right)_{4}$ & - & $\mathrm{Me}$ & $\mathrm{Br}$ & 0.5 & $72^{\mathrm{b}}$ \\
$\mathrm{Ph}$ & $\mathrm{H}$ & $\mathrm{H}$ & $\mathrm{Cl}$ & 1.7 & 99 \\
$\mathrm{Ph}$ & $\mathrm{H}$ & $\mathrm{H}$ & $\mathrm{Br}$ & 2.0 & 79 \\
$\mathrm{Ph}$ & $\mathrm{H}$ & $\mathrm{Me}$ & $\mathrm{Cl}$ & 0.5 & 89 \\
$\mathrm{Ph}$ & $\mathrm{H}$ & $\mathrm{Me}$ & $\mathrm{Br}$ & 1.5 & 59 \\
$\mathrm{Hex}$ & $\mathrm{H}$ & $\mathrm{H}$ & $\mathrm{Cl}$ & 2.7 & 99 \\
Hex & $\mathrm{H}$ & $\mathrm{H}$ & $\mathrm{Br}$ & 1.1 & 60
\end{tabular}

${ }^{\mathrm{a}}$ Yield of pure product based on the alkene, ${ }^{\mathrm{b}}$ trans-product.
Control experiments with styrene and both systems TCCA/ $\mathrm{Br}^{-}$and TBCA $/ \mathrm{Cl}^{-}$produced diverse products and in both reactions 2-bromo-1-chloro-1-phenylethane is formed. These results suggests the in situ formation of $\mathrm{BrCl}$ as the halogenation agent for both reactions. ${ }^{12}$ However, based on the works of Ross and coworkers ${ }^{13}$ Shao and Shi, ${ }^{6}$ the formation of a complex halogenating reagent formed between the trihaloisocyanuric acid and the halide ion could not be discarded.

\section{Conclusions}

In summary, we have found a very convenient method for the vicinal dihalogenation of alkenes in the absence of molecular halogen and polyhalogenated solvents. Furthermore, the reagents are safe and of easy handling, and the by-product for both reactions is cyanuric acid that can be recycled. Due to environmental problems involved in the manipulation of hazardous, toxic and corrosive halogens as well as the not readily available alternative reagents used in such transformation, our methodology becomes very attractive and consistent with green chemistry principles.

\section{Acknowledgments}

We thank $\mathrm{CNPq}$ and CAPES for financial support. SDFT thanks PIBIC-UFRJ, LSA, MCSM and PME thank CNPq for fellowships.

\section{References}

1. Spargo, P.L.; Contemp. Org. Synth. 1994, 1, 113.

2. Gribble, G.W.; Chemosphere 2003, 52, 289.

3. Larock, R.C.; Comprehensive Organic Transformations: A Guide to Functional Group Preparation, $2^{\text {nd }}$ ed, Wiley-VCH: New York, 1999, p. 630.

4. The Merk Index, $13^{\text {rd }}$ ed, Merck \& Co. Inc.: Whitehouse Station, 2001.

5. Sanseverino, A.M.; Quim. Nova 2000, 23, 102; Lenardão, E.J.; Freitag, R.A.; Dabdoub, M.J.; Batista, A.C.F.; Silveira, C.C.; Quim. Nova 2003, 26, 123; Anastas, P.T.; Warner, J.C.; Green Chemistry: Theory and Practice, Oxford University Press: Oxford, 2000

6. Shao, L.X.; Shi, M.; Synlett 2006, 1269.

7. Recent examples: Chaudhuri, S.K.; Roy, S.; Saha M.; Bhar, S.; Synth. Commun. 2007, 37, 271; Koshy, E.P.; Zacharias, J.; Pillai, V.N.R.; React. Func. Polym. 2006, 66, 845; Kavala, V.; Naik, S.; Patel, B.K.; J. Org. Chem. 2005, 70, 4267; McKenzie, L.C.; Huffman, L.M.; Hutchison, J.E.; J. Chem. Ed. 2005, 82, 306; Ye, C.; Shreeve, J.M.; J. Org. Chem. 2004, 69, 2004; Braddock, 
D.C.; Cansell, G.; Hermitage, S.A.; Synlett 2004, 461; Hazra, B.G.; Pore, V.S.; J. Indian Chem. Soc. 2003, 80, 1065.

8. Tilstan, U.; Weinmann, H.; Org. Process Res. Dev. 2002, 6, 384; Barros, J.C.; Synlett 2005, 2115; Kolvani, E.; GhorbaniChoghamarani, A.; Salehi, P.; Shirini, F.; Zolfigol, M.A.; J. Iran Chem. Soc. 2007, 4, 126.

9. de Almeida, L.S.; Esteves, P.M.; de Mattos, M.C.S.; Synlett 2006, 1515.

10. Mendonça, G.F.; Sanseverino, A.M.; de Mattos, M.C.S. Synthesis 2003, 45; Mendonça, G.F.; Magalhães, R.R.; de Mattos, M.C.S.; Esteves, P.M.; J. Braz. Chem. Soc. 2005, 16, 695; de Almeida, L.S.; Esteves, P.M.; de Mattos, M.C.S.; Synthesis 2006, 221; de Almeida, L.S.; Esteves, P.M.; de Mattos, M.C.S.; Synlett 2007, 1687.

11. Typical procedure: to a stirred solution of the alkene $(5 \mathrm{mmol})$ and $\mathrm{NaX}(10 \mathrm{mmol})$ in $\mathrm{Me}_{2} \mathrm{CO}\left(25 \mathrm{~cm}^{3}\right)$ and $\mathrm{H}_{2} \mathrm{O}\left(2 \mathrm{~cm}^{3}\right)$, the trihaloisocyanuric acid $(1.67 \mathrm{mmol})$ was slowly added at room temperature. After the end of the reaction (determined by the colour disappearance of a wet iodide-starch test paper treated with an aliquot of the reaction media), it was extracted with $\mathrm{CH}_{2} \mathrm{Cl}_{2}\left(3 \times 10 \mathrm{~cm}^{3}\right)$, and the organic layer was subsequently washed with water $\left(10 \mathrm{~cm}^{3}\right), 10 \% \mathrm{NaHSO}_{3}\left(10 \mathrm{~cm}^{3}\right)$, water $(10$ $\left.\mathrm{cm}^{3}\right)$ and dried $\left(\mathrm{Na}_{2} \mathrm{SO}_{4}\right)$. After filtration and evaporation of the solvent at reduced pressure the pure vicinal dihalide was obtained and characterized by HRGC-MS, physical constants and co-injection with authentic samples in HRGC.

12. Based on these suggestion, the systems $\mathrm{TCCA} / \mathrm{Cl}^{-}$and $\mathrm{TBCA} / \mathrm{Br}$ would generate $\mathrm{Cl}_{2}$ and $\mathrm{Br}_{2}$ in situ, respectively, and one could explain the better yields of vicinal dichlorides, as $\mathrm{Cl}_{2}$ is more reactive than $\mathrm{Br}_{2}$.

13. Finkelstein, M.; Hart, S.A.; Moore, W.M.; Ross, S.D.; Eberson, L.; J. Org. Chem. 1986, 51, 3548.

Received: May 7, 2007 Web Release Date: July 6, 2007 